Journal of Computer Science 8 (10): 1700-1710, 2012

ISSN 1549-3636

(C) 2012 Science Publications

\title{
Design of Speed Controller for Permananent Magnet Synchronous Motor Drive Using Genetic Algorithm Based Lower Order System Modelling
}

\author{
${ }^{1} \mathrm{~K}$. Ayyar, ${ }^{1} \mathrm{~K}$. Ramesh and ${ }^{2} \mathrm{G}$. Gurusamy \\ ${ }^{1}$ Department of Electrical and Electronics Engineering, \\ Velalar College of Engineering and Technology, Erode, Tamilnadu, India \\ ${ }^{2}$ Department of Electrical and Electronics Engineering, \\ Bannariamman Institute of Technology, Sathyamangalam, Erode, Tamilnadu, India
}

\begin{abstract}
Problem statement: In this study, a Model Order Reduction (MOR) method is proposed for reducing higher order system into lower order system. Speed controller design is carried out to the lower order system by Genetic Algorithm (GA) approach and this controller is used to higher order system. Approach: This study is used to find a solution to a given objective function employing different procedures and computational techniques. The problem area chosen is that of lower order system modelling used in design of speed controller for Permananent Magnet Synchronous Motor (PMSM) drive. Results: Genetic Algorithm obtains a better controller values that reflects the characteristics of the original higher order system and the performance evaluated using this method are compared with the existing approximation method. Conclusion: Performance of this Speed controller has been verified through Simulation using MATLAB package.
\end{abstract}

Keywords: Permananent Magnet Synchronous Motor (PMSM), drive, genetic algorithm, lower order system modelling, speed controller

\section{INTRODUCTION}

During the early 1950 s researchers studied evolutionary systems as an optimisation tool, with an introduction to the basics of evolutionary computing (Sivanandam and Deepa, 2009). Until 1960s evolutionary systems was working in parallel with Genetic Algorithm (GA) research. At this stage, evolutionary programming was developed with the concepts of evolution, selection and mutation. Holland (1992) introduced the concept of Genetic Algorithm as a principle of Charles Darwinian theory of evolution to natural biology. The working of genetic algorithm starts with a population of random chromosomes. The algorithm then evaluates these structures and allocates reproductive opportunities such that chromosomes, which have a better solution to the problem, are give more chance to reproduce. While selecting the best candidates, new fitter offspring are produced and reinserted and the less fit is removed. The exchange of characteristics of chromosomes takes place-using operators like crossover and mutation. The solution is defined with respect to the current population. GA operation basically depends on the Schema theorem. GAs are recognized as best function optimisers and is used broadly in pattern discovery, image processing, signal processing and in training Neural Networks.
Many control system applications, such as satellite altitude control, fighter aircraft control, model-based predictive control, control of fuel injectors, automobile spark timer, possess a mathematical model of the process with higher order, due to which the system defined becomes complex. These higher order models are cumbersome to handle (Sivanandam and Deepa, 2009). As a result, lower order system modelling can be performed, which helps in alleviating computational complexity and implementation difficulties involved in the design of controllers and compensators for higher order systems. Further, the development and usage of micro controllers and microprocessors in the design and implementation of control system components has increased the importance of lower order system modeling (Prasad, 2000; 2003a; 2003b). Thus, in this study, Genetic Algorithm is used independently to higher order systems and a suitable lower order system is modelled (Sivanandam and Deepa, 2009).

The availability of modern Permanent Magnets (PM) with considerable energy density led to the development of dc machines with PM field excitation in the 1950's. Introduction of PM to replace electromagnets, which have windings and require an external electric energy source, resulted in compact dc machines (Islam et al., 2011). The synchronous machine, with its conventional field excitation in the 
rotor, is replaced by the PM excitation; the slip rings and brush assembly are dispensed with. With the advent of switching power transistor and silicon-controlled rectifier devices in later part of 1950s, the replacement of the mechanical commutator with an electronic commutator in the form of an inverter was achieved. These two developments contributed to the development of PM synchronous and brushless dc machines (Islam et al., 2011). The armature of the dc machine need not be on the rotor if the mechanical commutator is replaced by its electronic version. Therefore, the armature of the machine can be on the stator, enabling better cooling and allowing higher voltages to be achieved: significant clearance space is avilable for insulation in the stator. The excitation field that used to be on the stator is transferred to the rotr with the PM poles. These machines are nothing but 'an inside out dc machine' with the field and armature interchanged from the stator to rotor and rotor to stator respectively (Pillay and Krishnan, 1989). In this study contains design of speed controller for permanant magnet synchronous machines using Genetic algorithm based lower order modelling.

Speed controller design: The design of the speedcontroller is important from the point of view of imparting desired transient and steady state characteristics to the speed-controlled PMSM drive systems (Islam et al., 2011). A proportional-plus-integral controller is sufficient for many industrial applications; hence, it is considered in this work. Selection of the gain and time constants of such a controller (Talebi et al., 2007) by using the symmetricoptimum principle is straightforward if the $\mathrm{d}$ axis stator current is assumed to be zero (Wallace, 1994). In the presence of a d axis stator current, the $d$ and q current channels are cross-coupled and the model is non-linear, as a result of the torque term. Under the assumption that the $\mathrm{d}$ axis current being zero (i.e., $\mathrm{i}_{\mathrm{ds}}^{\mathrm{r}}=0$ ), then the system becomes linear and resembles that of a separately-excited dc motor with constant excitation (Sharma et al., 2008). From then on, the block-diagram derivation, current loop approximation, speed-loop approximation and derivation of the speed controller by using symmetric optimum are identical to those for a dc motor drive speed controller design.

Block diagram derivation: The motor $\mathrm{q}$ axis voltage equation with the $\mathrm{d}$ axis current being zero becomes (Sharma et al., 2008):

$$
\mathrm{V}_{\mathrm{qs}}^{\mathrm{r}}=\left(\mathrm{R}_{\mathrm{s}}+\mathrm{L}_{\mathrm{q}} \mathrm{p}\right) \mathrm{i}_{\mathrm{qs}}^{\mathrm{r}}+\omega_{\mathrm{r}} \lambda_{\mathrm{af}}
$$

And the electromechanical Eq. 2 is:

$$
\frac{\mathrm{P}}{2}\left(\mathrm{~T}_{\mathrm{e}}-\mathrm{T}_{1}\right)=\mathrm{Jp} \omega_{\mathrm{r}}+\mathrm{B}_{1} \omega_{\mathrm{r}}
$$

where, the electromagnetic torque is given by Eq. 3:

$$
\mathrm{T}_{\mathrm{e}}=\frac{3}{2} \cdot \frac{\mathrm{P}}{2} \lambda_{\mathrm{af}} \mathrm{i}_{\mathrm{qs}}^{\mathrm{r}}
$$

And if the load is assumed to be frictional, then Eq. 4:

$\mathrm{T}_{1}=\mathrm{B}_{1} \omega_{\mathrm{m}}$

Which, upon substitution, gives the electromechanical Eq. 5 as:

$\left(\mathrm{Jp}+\mathrm{B}_{\mathrm{t}}\right) \omega_{\mathrm{r}}=\left\{\frac{3}{2}\left(\frac{\mathrm{P}}{2}\right)^{2} \cdot \lambda_{\mathrm{af}}\right\} \mathrm{i}_{\mathrm{qs}}^{\mathrm{r}}=\mathrm{K}_{\mathrm{t}} \cdot \mathrm{i}_{\mathrm{qs}}^{\mathrm{r}}$

The frictional torque coefficient is Eq. 6:

$\mathrm{B}_{\mathrm{t}}=\frac{\mathrm{P}}{2} \mathrm{~B}_{1}+\mathrm{B}_{1}$

And torque consatnt is Eq. 7:

$\mathrm{K}_{\mathrm{t}}=\frac{3}{2}\left(\frac{\mathrm{P}}{2}\right)^{2} \cdot \lambda_{\mathrm{af}}$

The Eq. 1 and 5, when combined into a block diagram with the current-and speed-feedback loops added (Sharma et al., 2008) are shown in Fig. 1.

The inverter is modeled as a gain with a time lag (Talebi et al., 2007) by Eq. 8-10:

$\mathrm{G}_{\mathrm{r}}(\mathrm{s})=\frac{\mathrm{K}_{\mathrm{in}}}{1+\mathrm{s} \mathrm{T}_{\mathrm{in}}}$

Where:

$\mathrm{K}_{\mathrm{in}}=0.65 \frac{\mathrm{V}_{\mathrm{dc}}}{\mathrm{V}_{\mathrm{cm}}}$

$\mathrm{T}_{\mathrm{in}}=\frac{1}{2 \mathrm{f}_{\mathrm{c}}}$

where, $\mathrm{V}_{\mathrm{dc}}$ is the dc-link voltage input to the inverter (Islam et al., 2011), $\mathrm{V}_{\mathrm{cm}}$ is the maximum control voltage and $f_{c}$ is the switching (carrier) frequency of the inverter. Eq. 11:

The induced emf due to rotor flux linkages, $\mathrm{e}_{\mathrm{a}}$, is

$\mathrm{e}_{\mathrm{a}}=\lambda_{\mathrm{af}} \omega_{\mathrm{r}}(\mathrm{V})$

Current loop: This induced-emf loop crosses the $q$ axis current loop and it could be simplified by moving the pick-off point for the induced-emf loop from speed to current output point. This gives the currnt-loop transfer function (Sharma et al., 2008) from Fig. 2. 


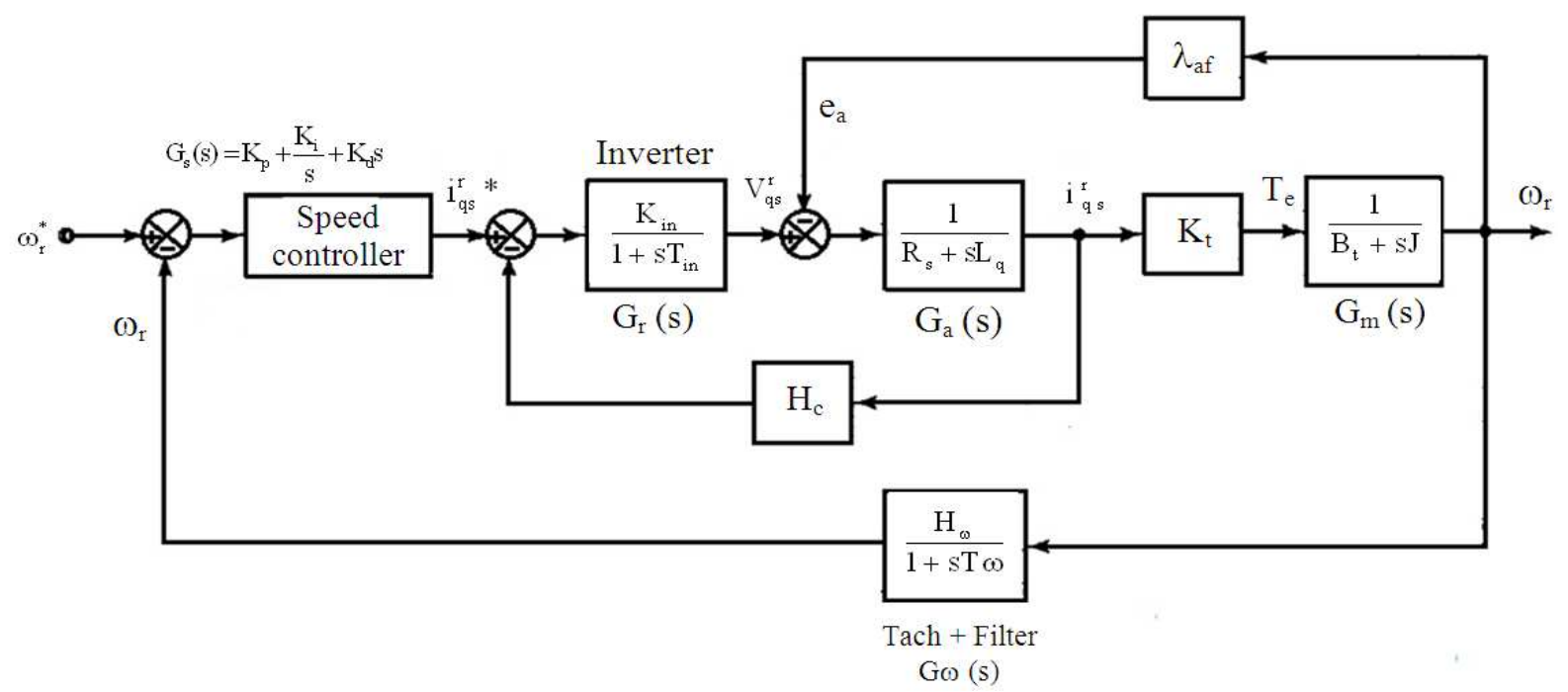

Fig. 1: Block diagram of the spped-controlled PMSM drive

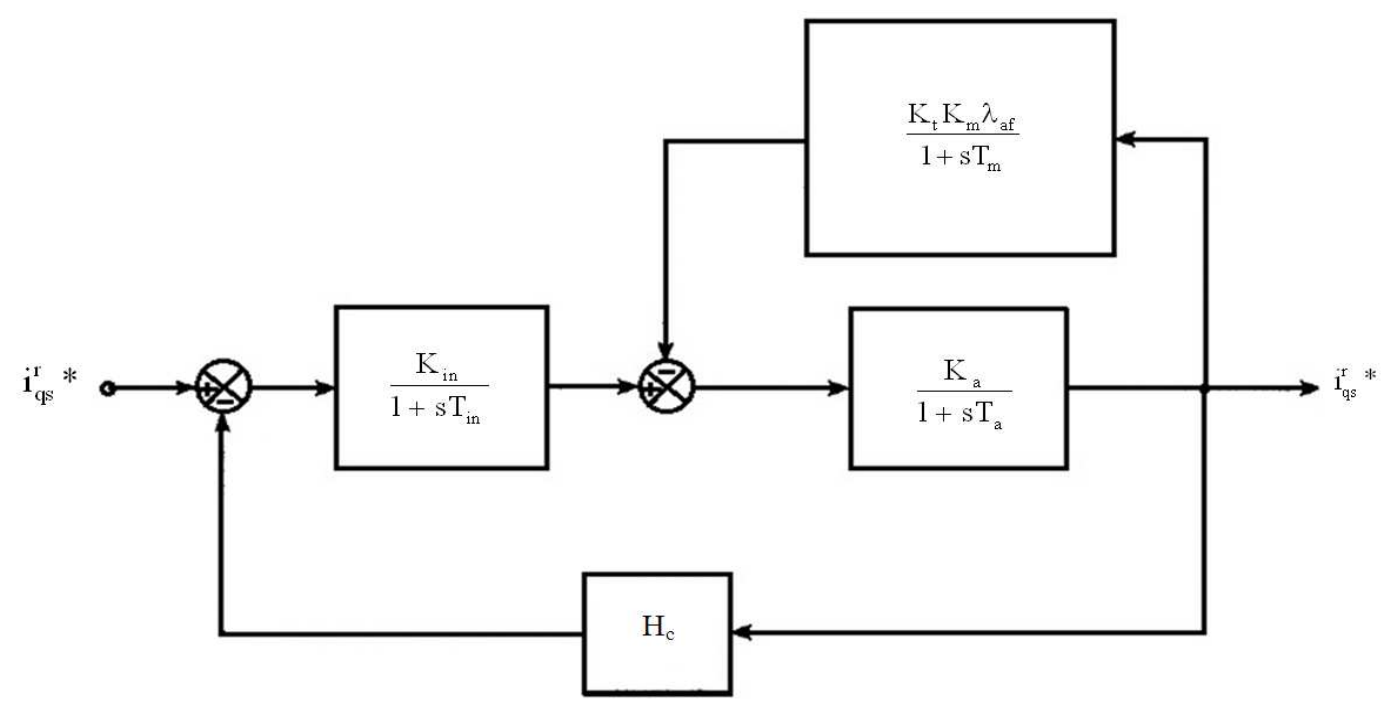

Fig. 2: Current controller

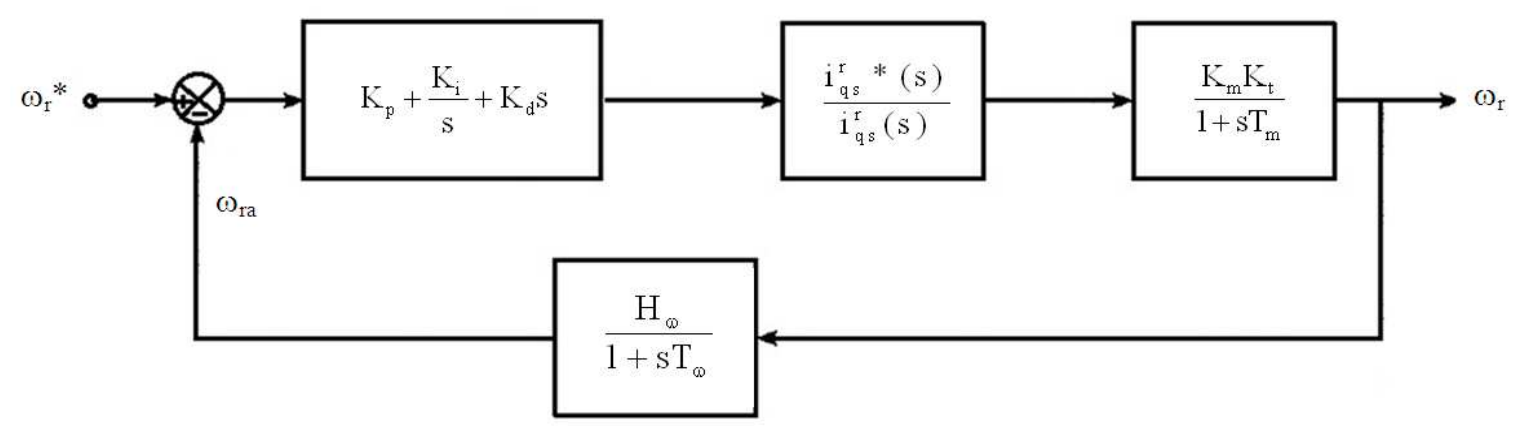

Fig. 3: Speed-control loop

1702 
This induced emf loop crosses the q axis current loop and it could be simplified by moving the pickoff point for the induced-emf loop from speed to current output point. This gives the current-loop transfer function from Fig. 2 as Eq. 12 and 13:

$$
\begin{aligned}
\frac{\mathrm{i}_{\mathrm{qs}}^{\mathrm{r}}(\mathrm{s})}{\mathrm{i}_{\mathrm{qs}}^{\mathrm{r}} *(\mathrm{~s})}= & \frac{\mathrm{K}_{\mathrm{in}} \mathrm{K}_{\mathrm{a}}\left(1+\mathrm{s} \mathrm{T}_{\mathrm{m}}\right)}{\mathrm{H}_{\mathrm{c}} \mathrm{K}_{\mathrm{a}} \mathrm{K}_{\mathrm{in}}\left(1+\mathrm{sT}_{\mathrm{m}}\right)+\left(1+\mathrm{sT}_{\mathrm{in}}\right)} \\
& \left\{\mathrm{K}_{\mathrm{a}} \mathrm{K}_{\mathrm{b}}+\left(1+\mathrm{sT}_{\mathrm{a}}\right)\left(1+\mathrm{sT}_{\mathrm{m}}\right)\right\}
\end{aligned}
$$

Where:

$$
\mathrm{K}_{\mathrm{a}}=\frac{1}{\mathrm{R}_{\mathrm{s}}} ; \mathrm{T}_{\mathrm{a}}=\frac{\mathrm{L}_{\mathrm{q}}}{\mathrm{R}_{\mathrm{s}}} ; \mathrm{K}_{\mathrm{m}}=\frac{1}{\mathrm{~B}_{\mathrm{t}}} ; \mathrm{T}_{\mathrm{m}}=\frac{\mathrm{J}}{\mathrm{B}_{\mathrm{t}}} ; \mathrm{K}_{\mathrm{b}}=\mathrm{K}_{\mathrm{t}} \mathrm{K}_{\mathrm{m}} \lambda_{\mathrm{af}}
$$

This current-loop transfer function (Krishnan and Ramaswami, 1974) is substituted in the design of the speed controller as follows.

Speed controller: The speed-control loop is shown in Fig. 3.

Drive parameters: The PMSM drive system parameters are as follows:

$\mathrm{R}_{\mathrm{s}}=1.4 \Omega, \mathrm{L}_{\mathrm{d}}=0.0056 \mathrm{H}, \mathrm{L}_{\mathrm{q}}=0.009 \mathrm{H}, \lambda_{\mathrm{af}}=0.1546 \mathrm{~Wb}-$ Turn, $\mathrm{B}_{\mathrm{t}}=0.01 \mathrm{~N}-\mathrm{m} / \mathrm{rad} / \mathrm{sec}, \mathrm{J}=0.006 \mathrm{~kg}-\mathrm{m}^{2}, \mathrm{P}=6, \mathrm{f}_{\mathrm{c}}$ $=2 \mathrm{kHz}, \mathrm{V}_{\mathrm{cm}}=10 \mathrm{~V}, \mathrm{H}_{\omega}=0.05 \mathrm{~V} / \mathrm{V}, \mathrm{T}_{\omega}=0.002 \mathrm{sec}, \mathrm{H}_{\mathrm{c}}$ $=0.8 \mathrm{~V} / \mathrm{A}, \mathrm{V}_{\mathrm{dc}}=285 \mathrm{~V}$.

From the above drive parameters the following values are obtained:

Inverter: Gain, $\mathrm{K}_{\mathrm{in}}=18.525 \mathrm{~V} / \mathrm{V}$; Time constant, $\mathrm{T}_{\mathrm{in}}=$ $0.00025 \mathrm{sec}$.

Motor (electrical): Gain, $\mathrm{K}_{\mathrm{a}}=0.7143$; Time constant, $\mathrm{T}_{\mathrm{a}}$ $=0.0064 \mathrm{sec}$.

Induced emf loop: Torque constant, $\mathrm{K}_{\mathrm{t}}=2.087 \mathrm{~N} . \mathrm{m} / \mathrm{A}$

Mechanical gain, $\mathrm{K}_{\mathrm{m}}=100 \mathrm{rad} / \mathrm{s} / \mathrm{Nm}$; Mechanical Time constant, $\mathrm{T}_{\mathrm{m}}=0.6 \mathrm{sec}$.

$\mathrm{K}_{\mathrm{b}}=\mathrm{K}_{\mathrm{t}} \mathrm{K}_{\mathrm{m}} \lambda_{\mathrm{af}}=32.26$.

Proposed method of model reduction: The proposed method of model reduction is Cross Multiplication of Polynomials Model order reduction method. It consists of the following steps in the system approximation process.

Step-1: The denominator and numerator polynomial constant terms in the reduced order model are obtained through Pade approximation: The transfer function of higher order $\left(\mathrm{n}^{\text {th }}\right)$ is considered as Eq. 14:
$\mathrm{G}(\mathrm{s})=\frac{\mathrm{a}_{0}+\mathrm{a}_{1} \mathrm{~s}+\mathrm{a}_{2} \mathrm{~s}^{2}+\ldots+\mathrm{a}_{\mathrm{n}-1} \mathrm{~s}^{\mathrm{n}-1}}{\mathrm{~b}_{0}+\mathrm{b}_{1} \mathrm{~s}+\mathrm{b}_{2} \mathrm{~s}^{2}+\ldots+\mathrm{b}_{\mathrm{n}-1} \mathrm{~s}^{\mathrm{n}-1}+\mathrm{b}_{\mathrm{n}} \mathrm{s}^{\mathrm{n}}}$

$\mathrm{G}$ (S) can be expanded into a power series about $\mathrm{S}$ $=0$ of the form Eq. 15-17 (Shamash, 1975):

$\mathrm{G}(\mathrm{s})=\mathrm{c}_{0}+\mathrm{c}_{1} \mathrm{~s}+\mathrm{c}_{2} \mathrm{~s}^{2}+\cdots$

Where:

$\mathrm{c}_{0}=\frac{\mathrm{a}_{0}}{\mathrm{~b}_{0}}$

And:

$$
c_{k}=\frac{1}{b_{0}}\left[a_{k}-\sum_{j=1}^{k} b_{j} c_{k-j}\right], \quad k>0
$$

With:

$$
\mathrm{d}_{\mathrm{k}}=0 \quad \forall \mathrm{k}>\mathrm{n}-1
$$

The $d_{i}$ are directly proportional to the time moments of the system, assuming the system is stable Eq. 18 (Shamash, 1975):

$\mathrm{G}_{\mathrm{r}}(\mathrm{s})=\frac{\mathrm{d}_{0}+\mathrm{d}_{1} \mathrm{~s}+\mathrm{d}_{2} \mathrm{~s}^{2}+\ldots+\mathrm{d}_{\mathrm{r}-1} \mathrm{~s}^{\mathrm{r}-1}}{\mathrm{e}_{0}+\mathrm{e}_{1} \mathrm{~s}+\mathrm{e}_{2} \mathrm{~s}^{2}+\ldots+\mathrm{e}_{\mathrm{r}-1} \mathrm{~s}^{\mathrm{r}-1}+\mathrm{e}_{\mathrm{r}} \mathrm{s}^{\mathrm{r}}}$

Then for R (s) to be Pade approximant of G (S), the following Eq. 19 and 20 are obtained:

$\mathrm{d}_{0}=\mathrm{e}_{0} \cdot \mathrm{c}_{0}$

$\mathrm{d}_{1}=\mathrm{e}_{0} \cdot \mathrm{c}_{1}+\mathrm{e}_{1} \cdot \mathrm{c}_{0}$

$0=e_{0} \cdot c_{2 r-2}+e_{1} \cdot c_{2 r-1}+\cdots c_{r-1}$

$0=\mathrm{e}_{0} \cdot \mathrm{c}_{2 \mathrm{r}-1}+\cdots \mathrm{c}_{\mathrm{r}}$

From the Eq. 16 and 20:

$\mathrm{c}_{0}=\frac{\mathrm{a}_{0}}{\mathrm{~b}_{0}}=\frac{\mathrm{d}_{0}}{\mathrm{e}_{0}}$

From the Eq. 21, let Eq. 22:

$$
\left.\frac{\mathrm{a}_{0}}{\mathrm{~b}_{0}}=\frac{\mathrm{d}_{0}}{\mathrm{e}_{0}}\right\}
$$


Step-2: The unknown coefficients of different powers of ' $s$ ' remaining in reduced order model are determined: The given higher order system transfer function is equated and cross multiplied with $\mathrm{k}^{\text {th }}$ order general transfer function. This process yields $(n+2)$ equations with (2r-1) unknown reduced order transfer function coefficients. This step is similar to the model order reduction method proposed in Manigandan et al. (2005), where the values of $\mathrm{e}_{0}$ or $\mathrm{d}_{0}$ are kept as equal to ' 1 ' irrespective of the system condition to obtain the values of unknown coefficients in the reduced order model transfer function. But in this proposed method, the values of $\mathrm{e}_{0}$ and $\mathrm{d}_{0}$ are obtained through Pade approximation method as detailed in step-1. This leads to better system approximation as compared to the model order reduction method proposed by Eq. 23 and 24 Manigandan et al. (2005):

$$
\begin{aligned}
& \frac{a_{0}+a_{1} s+a_{2} s^{2}+\ldots+a_{n-1} s^{n-1}}{b_{0}+b_{1} s+b_{2} s^{2}+\ldots+b_{n-1} s^{n-1}+b_{n} s^{n}} \\
& =\frac{d_{0}+d_{1} s+d_{2} s^{2}+\ldots+d_{r-1} s^{r-1}}{e_{0}+e_{1} s+e_{2} s^{2}+\ldots+e_{r-1} s^{r-1}+e_{r} s^{r}} \\
& \left(a_{0}+a_{1} s+a_{2} s^{2}+\ldots+a_{n-1} s^{n-1}\right) \\
& \left(e_{0}+e_{1} s+e_{2} s^{2}+\ldots+e_{r-1} s^{r-1}+e_{r} s^{r}\right) \\
& =\left(b_{0}+b_{1} s+b_{2} s^{2}+\ldots+b_{n-1} s^{n-1}+b_{n} s^{n}\right) \\
& \left(d_{0}+d_{1} s+d_{2} s^{2}+\ldots+d_{r-1} s^{r-1}\right)
\end{aligned}
$$

The coefficients of same power of ' $\mathrm{s}$ ' on both side of the Eq. 24 equated with each other (Ramesh et al., 2008) and is given by Eq. 25:

$$
\begin{aligned}
a_{n-1} \cdot e_{r} & =b_{n} \cdot d_{r-1} \\
a_{n-1} \cdot e_{r-1}+a_{n-2} \cdot e_{r} & =b_{n-1} \cdot d_{r-1}+b_{n} \cdot d_{r-2} \\
& \vdots \\
a_{2} \cdot e_{0}+a_{1} \cdot e_{1}+a_{0} \cdot e_{2} & =b_{0} \cdot d_{2}+b_{1} \cdot d_{1}+b_{2} \cdot d_{0} \\
a_{1} \cdot e_{0}+a_{0} \cdot e_{1} & =b_{1} \cdot d_{0}+b_{0} \cdot d_{1} \\
a_{0} \cdot e_{0} & =b_{0} \cdot d_{0}
\end{aligned}
$$

The $(n+2)$ set of Eq. 25 is solved with the values of $\mathrm{d}_{0}, \mathrm{e}_{0}$ obtained in (22). This leads to have different set equations for solving the remaining unknown parameters. Based on the optimal ISE value, the unknown values are selected and the resultant reduced order model is obtained as Eq. 26 and 27:

$$
\begin{aligned}
& \mathrm{G}_{\mathrm{r}}(\mathrm{s})=\frac{\mathrm{d}_{0}+\mathrm{d}_{1} \mathrm{~s}+\mathrm{d}_{2} \mathrm{~s}^{2}+\ldots+\mathrm{d}_{\mathrm{r}-1} \mathrm{~s}^{\mathrm{r}-1}}{\mathrm{e}_{0}+\mathrm{e}_{1} \mathrm{~s}+\mathrm{e}_{2} \mathrm{~s}^{2}+\ldots+\mathrm{e}_{\mathrm{r}-1} \mathrm{~s}^{\mathrm{r}-1}+\mathrm{e}_{\mathrm{r}} \mathrm{s}^{\mathrm{r}}} \\
& \text { If } \mathrm{r}=2 \Rightarrow \\
& \mathrm{G}_{2}(\mathrm{~s})=\frac{\mathrm{d}_{0}+\mathrm{d}_{1} \mathrm{~s}}{\mathrm{e}_{2} \mathrm{~s}^{2}+\mathrm{e}_{1} \mathrm{~s}+\mathrm{e}_{0}}
\end{aligned}
$$

Step-3: The cumulative error index (J) for initial reduced order model is calculated (Sivanandam and
Deepa, 2009): Consider, the transfer function of higher $\operatorname{order}\left(\mathrm{n}^{\text {th }}\right)$ as:

$$
\mathrm{G}(\mathrm{s})=\frac{\mathrm{a}_{0}+\mathrm{a}_{1} \mathrm{~s}+\mathrm{a}_{2} \mathrm{~s}^{2}+\ldots+\mathrm{a}_{\mathrm{n}-1} \mathrm{~s}^{\mathrm{n}-1}}{\mathrm{~b}_{0}+\mathrm{b}_{1} \mathrm{~s}+\mathrm{b}_{2} \mathrm{~s}^{2}+\ldots+\mathrm{b}_{\mathrm{n}-1} \mathrm{~s}^{\mathrm{n}-1}+\mathrm{b}_{\mathrm{n}} \mathrm{s}^{\mathrm{n}}}
$$

The general form of the transfer function of a second order system in the $s$-domain can be represented as:

$$
\mathrm{G}_{\mathrm{ri}}(\mathrm{s})=\frac{\mathrm{T}_{1}+\mathrm{T}_{2} \mathrm{~S}}{\mathrm{~s}^{2}+2 \zeta \omega_{\mathrm{n}} \mathrm{S}+\omega_{\mathrm{n}}{ }^{2}}
$$

where, $\zeta$ is the damping ratio and $\omega_{\mathrm{n}}$ is the undamped natural frequency of oscillation in $\mathrm{rad} / \mathrm{sec}$. The values of $\mathrm{T}_{1}$ and $\mathrm{T}_{2}$ corresponding to Eq. 28 can be computed as $\mathrm{T}_{1}=\mathrm{T}_{\mathrm{g}}$ and $\mathrm{T}_{2}=\mathrm{S}_{\mathrm{g}} / \omega_{\mathrm{n}}^{2}$. Where, the transient gain $\left(\mathrm{T}_{\mathrm{g}}\right)$ and steady state gain $\left(\mathrm{S}_{\mathrm{g}}\right)$ are computed as:

$$
\mathrm{Tg}=\frac{\mathrm{a}_{\mathrm{n}-1}}{\mathrm{~b}_{\mathrm{n}}} \text { and } \mathrm{Sg}=\frac{\mathrm{a}_{0}}{\mathrm{~b}_{0}}
$$

By using proposed scenario-1, the reduced order model obtained in step-2/step-3 is modified in to an initial form as Eq. 29:

$G_{\mathrm{ri}}(s)=\frac{\frac{\mathrm{d}_{0}}{\mathrm{e}_{2}}+\frac{\mathrm{d}_{1}}{\mathrm{e}_{2}} \mathrm{~s}}{\frac{\mathrm{e}_{0}}{\mathrm{e}_{2}}+\frac{\mathrm{e}_{1}}{\mathrm{e}_{2}} \mathrm{~s}+\mathrm{s}^{2}}=\frac{\mathrm{A}_{0}+\mathrm{A}_{1} \mathrm{~s}}{\mathrm{~B}_{0}+\mathrm{B}_{1} \mathrm{~s}+\mathrm{s}^{2}}$

Where:

$$
\begin{aligned}
& \mathrm{A}_{0}=\frac{\mathrm{d}_{0}}{\mathrm{e}_{2}}=\mathrm{T}_{1}, \mathrm{~A}_{1}=\frac{\mathrm{d}_{1}}{\mathrm{e}_{2}}=\mathrm{T}_{2}, \\
& \mathrm{~B}_{0}=\frac{\mathrm{e}_{0}}{\mathrm{e}_{2}} \text { and } \mathrm{B}_{1}=\frac{\mathrm{e}_{1}}{\mathrm{e}_{2}}
\end{aligned}
$$

The unit step input time response of the initial second order approximant $\mathrm{G}_{\mathrm{ri}}(\mathrm{S})$ is analyzed with a computer program and its characteristics are noted. The cumulative error index $\mathbf{J}$ using the integral square error of the unit step time responses of the given higher order system $\mathrm{G}(\mathrm{s})$ represented by Eq. 15 and the initial second order approximant $\mathrm{G}_{\mathrm{ri}}(\mathrm{S})$ represented by Eq. 29 is calculated. The cumulative error index $\mathrm{J}$ is calculated using the formula Eq. 30:

$$
J=\sum_{t=0}^{N}\left[y(t)-y_{r}(t)\right]^{2}
$$

where, $\mathrm{y}(\mathrm{t})$ is the output response of the higher order system at the $\mathrm{N}^{\text {th }}$ instant of time, $\mathrm{y}_{\mathrm{r}}(\mathrm{t})$ is the output response of the second order model at the $\mathrm{N}^{\text {th }}$ instant of time and $\mathrm{N}$ is the time interval in seconds over which the error index is computed. 


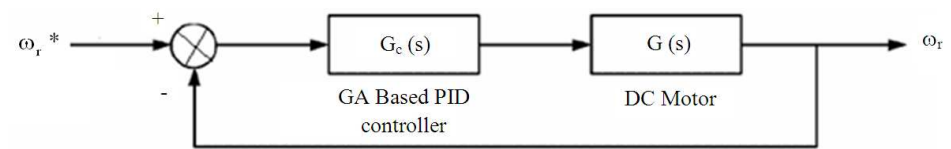

Fig. 4: Block diagram of the GA based PID controller of the system

Table 1: Parameters of GA

\begin{tabular}{ll}
\hline GA property & Value/method \\
\hline Population size & 60 \\
Maximum Number of generations & 20 \\
Performance index/fitness function & Mean square error \\
Selection Method & Normalized Geometric selection \\
Probability of selection & 0.05 \\
Crossover method & Arithmetic crossover \\
Number of crossover points & 3 \\
Mutation method & Uniform mutation \\
Mutation probability & 0.1 \\
\hline
\end{tabular}

tation probability

Table 2: GA based PID controller gain values

\begin{tabular}{llll}
\hline Gain parameters & $\mathrm{K}_{\mathrm{p}}$ & $\mathrm{K}_{\mathrm{i}}$ & $\mathrm{K}_{\mathrm{d}}$ \\
\hline Gain values & 17.70713 & 31.7933 & 0.00407 \\
\hline
\end{tabular}

After giving the above parameters to GA the PID controllers can be easily tuned and thus system performance can be improved (Thomas and Poongodi, 2009).

Step-4: Find the PID Controller Constants using GA: GA can be applied to the tuning of PID controller gains to ensure optimal control performance at nominal operating conditions. The block diagram for the entire system is given below in Fig. 4 and also the genetic algorithm parameters chosen (Thomas and Poongodi, 2009) for the tuning purpose are shown below in Table 1.The constants $\mathrm{K}_{\mathrm{p}}, \mathrm{K}_{\mathrm{i}}$ and $\mathrm{K}_{\mathrm{d}}$ are determined using Genetic Algorithm (GA) approach (Mahony et al., 2000). The Controller design for resultant reduced order model will closely match with the corresponding higher order model.

After giving the above parameters to GA the PID controllers can be easily tuned and thus system performance can be improved.

\section{Speed controller design by proposed method:}

Transfer function Approach:

Original Higher order system without speed controller and filter: Let $\mathrm{G}(\mathrm{s})$ be the transfer function of the original higher order system. The transfer function of PMSM drive system without speed controller and filter is as follows Eq. 31:

$$
\begin{aligned}
\mathrm{G}(\mathrm{s})= & \frac{1657.078 \mathrm{~s}+2763.2}{0.000000576 \mathrm{~s}^{4}+0.0024 \mathrm{~s}^{3}} \\
& +4.2 \mathrm{~s}^{2}+27.778 \mathrm{~s}+34.63
\end{aligned}
$$

Reduced order system: Let $G_{r}(s)$ be the transfer function of the reduced order system (Portone, 1997). The transfer function of the reduced order system of PMSM drive by the application of proposed method is as follows Eq. 32:

$$
G_{r}(s)=\frac{3237.95 s+2763.2}{8.21 s^{2}+47.59 s+34.63}
$$

From Eq. 29, the reduced order model is obtained as Eq. 33 (Ravichandran, 2007):

$G_{r}(s)=\frac{394.4 s+336.56}{s^{2}+5.796 s+4.22}$

Speed controller: To obtain an optimum transient response of the system, a PID controller is chosen with transfer function Eq. 34 (Kuo and Golnaraghi, 2003; Ogata, 2010):

$\mathrm{G}_{\mathrm{c}}(\mathrm{s})=\mathrm{K}_{\mathrm{p}}+\frac{\mathrm{K}_{\mathrm{i}}}{\mathrm{s}} \mathrm{K}_{\mathrm{d}} \mathrm{s}$

Where:

$\mathrm{K}_{\mathrm{p}}=$ Proportional gain

$\mathrm{K}_{\mathrm{i}}=$ Integral gain

$\mathrm{K}_{\mathrm{d}}=$ Derivative gain

The Values of $\mathrm{K}_{\mathrm{p}}, \mathrm{K}_{\mathrm{i}}$ and $\mathrm{K}_{\mathrm{d}}$ are obtained by Genetic Algorithm (GA) approach. The resultant $\mathrm{K}_{\mathrm{p}}, \mathrm{K}_{\mathrm{i}}$ and $\mathrm{K}_{\mathrm{d}}$ values are tabulated as shown in Table 2 .

Speed controller design for reduced system: The block diagram of reduced system with speed controller is shown in Fig. 5.

where, $\mathrm{K}_{\mathrm{p}}, \mathrm{K}_{\mathrm{i}}$ and $\mathrm{K}_{\mathrm{d}}$ values are $17.70713,31.7933$ and 0.00407 respectively.

Speed controller design for original system: The $K_{p}$, $K_{i}$ and $K_{d}$ values of speed controller of Original system is same as that of reduced system. Using this value the speed controller of original system is done. Fig. 6 shows the block diagram of original system with speed controller.

Design specifications: The system is tested with unit step input and the design procedure is followed based on the following design specifications:

$\begin{aligned} \text { Maximum peak overshoot }= & \text { less than } 3 \% \\ \text { Settling time } & \text { less than } 3 \mathrm{sec} \\ \text { Steady state error } & 2 \% \text { (assumed for } \\ & \text { optimum response) } \\ & \text { Before proceeding on to } \\ & \text { the simulation, the } \\ & \text { starting values of the } \\ & \text { parameters of controller } \\ & \text { are deduced using newly } \\ & \text { proposed procedures }\end{aligned}$




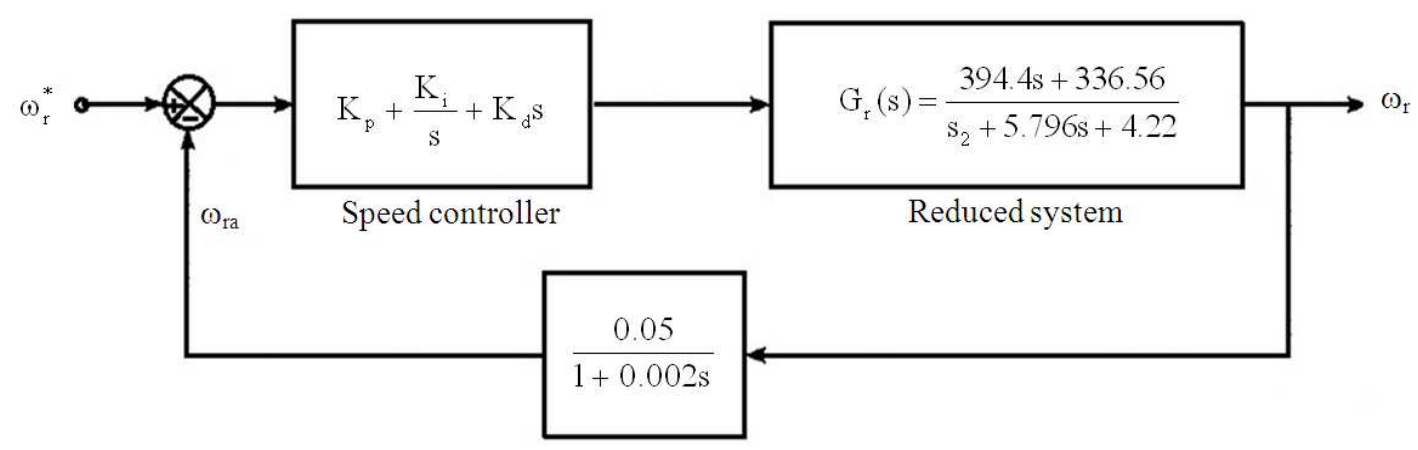

Fig. 5: Block diagram of reduced system with speed controller

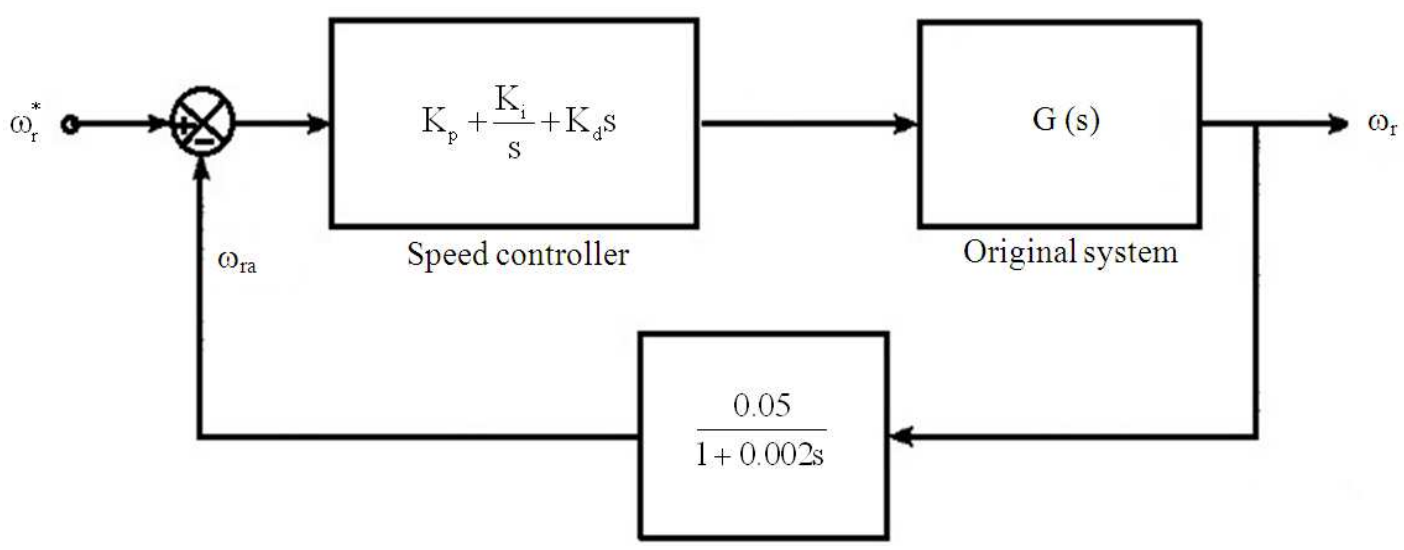

Fig. 6: Block diagram of original system with speed controller

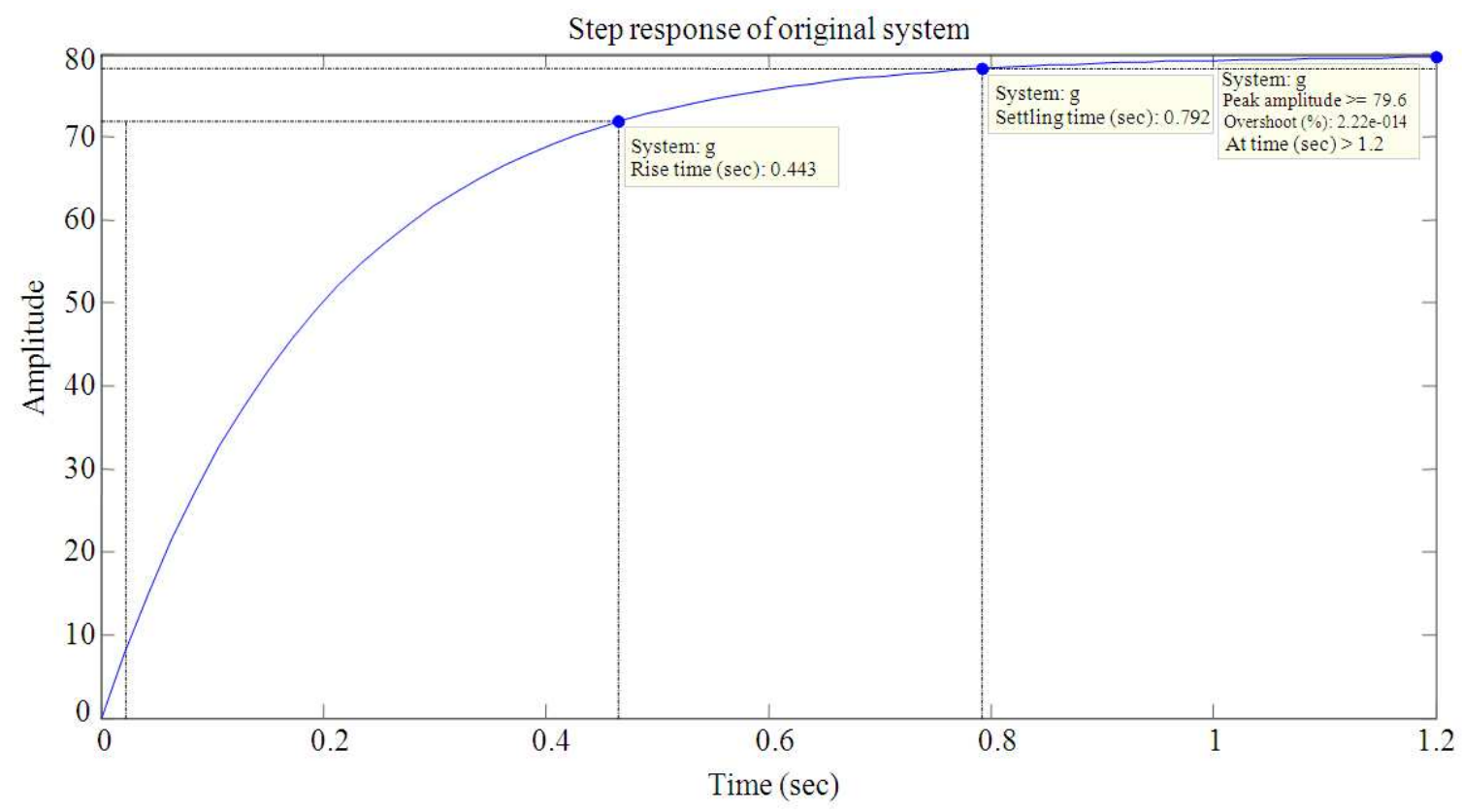

Fig. 7: Step response of original system without speed controller 1706 


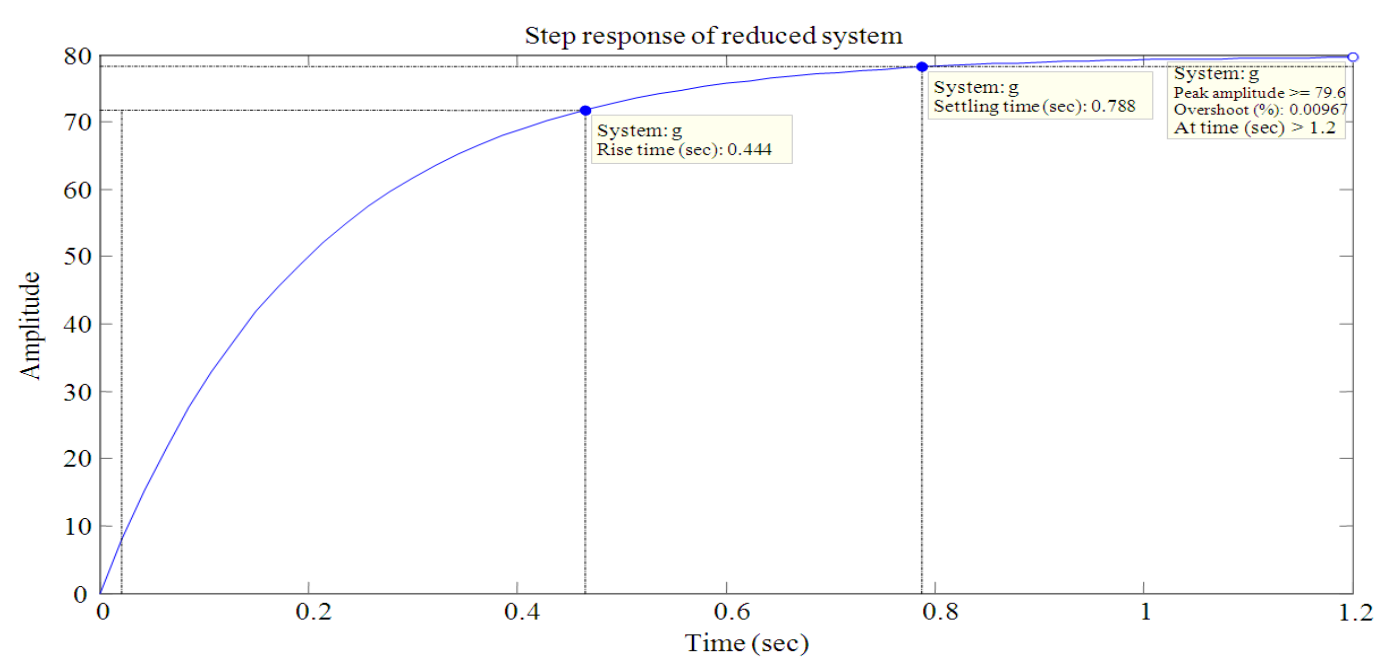

Fig. 8: Step response of reduced system without speed controller

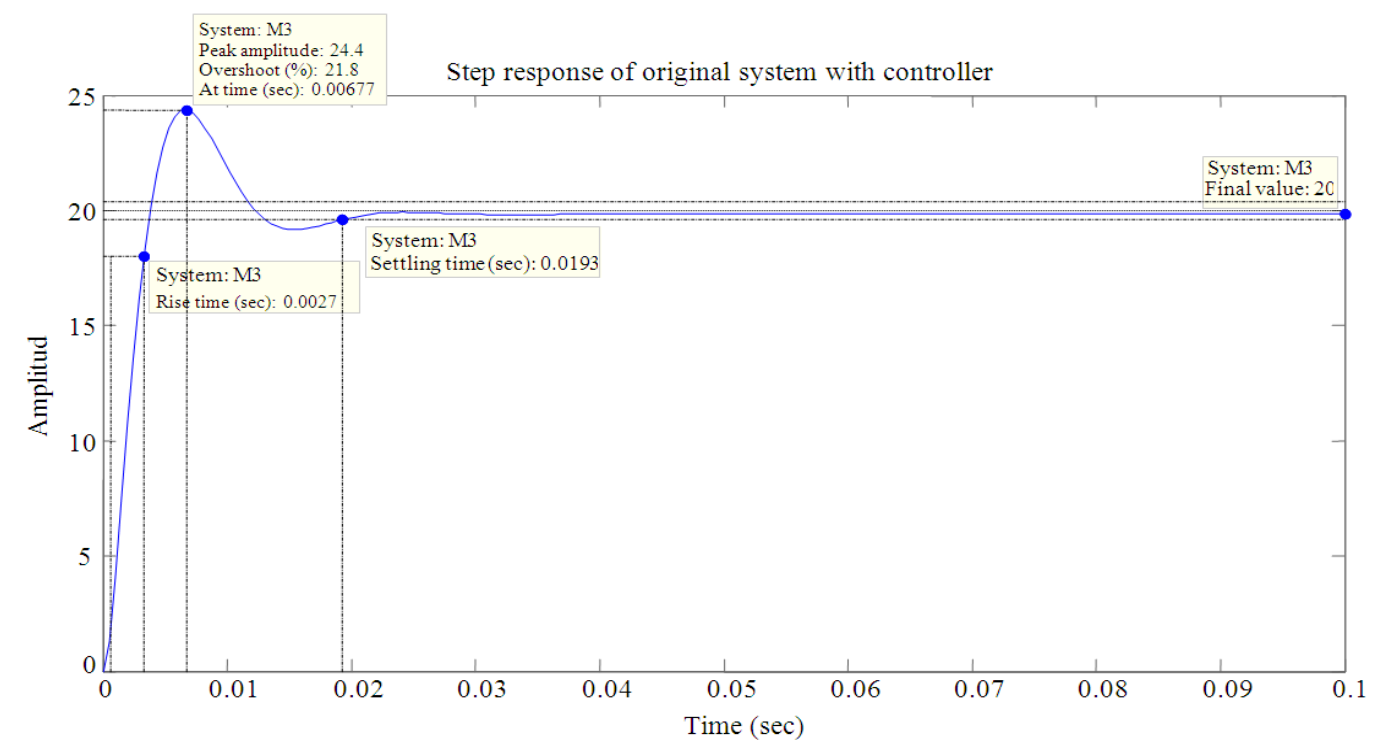

Fig. 9: Step response of original system with speed controller

Simulation results: The effectiveness of the newly proposed scheme for the design of PID Speed controller for PMSM drives are demonstrated using computer simulations. The system is simulated for step input using MATLAB-SIMULINK software with and without controllers (Chapman, 2002). The output responses of the above simulation studies are given in the following Figures.

Step response of original system: The step response of the PMSM drive system is shown in Fig. 7.

Step response of reduced system: The step response of the reduced order PMSM drive system is shown in Fig. 8.
Step response of original system with controller: The step response of the PMSM drive system with Speed controller by proposed method is shown in Fig. 9. Compared with PMSM drive with conventional speed controller it gives better performance as listed in Table 3 .

Step response of reduced system with controller: The step response of the reduced order PMSM drive system with Speed controller by proposed method is shown in Fig. 10.

Step response of original system with conventional controller: Step response of original system with conventional speed controller of PMSM drive is shown in Fig. 11. 


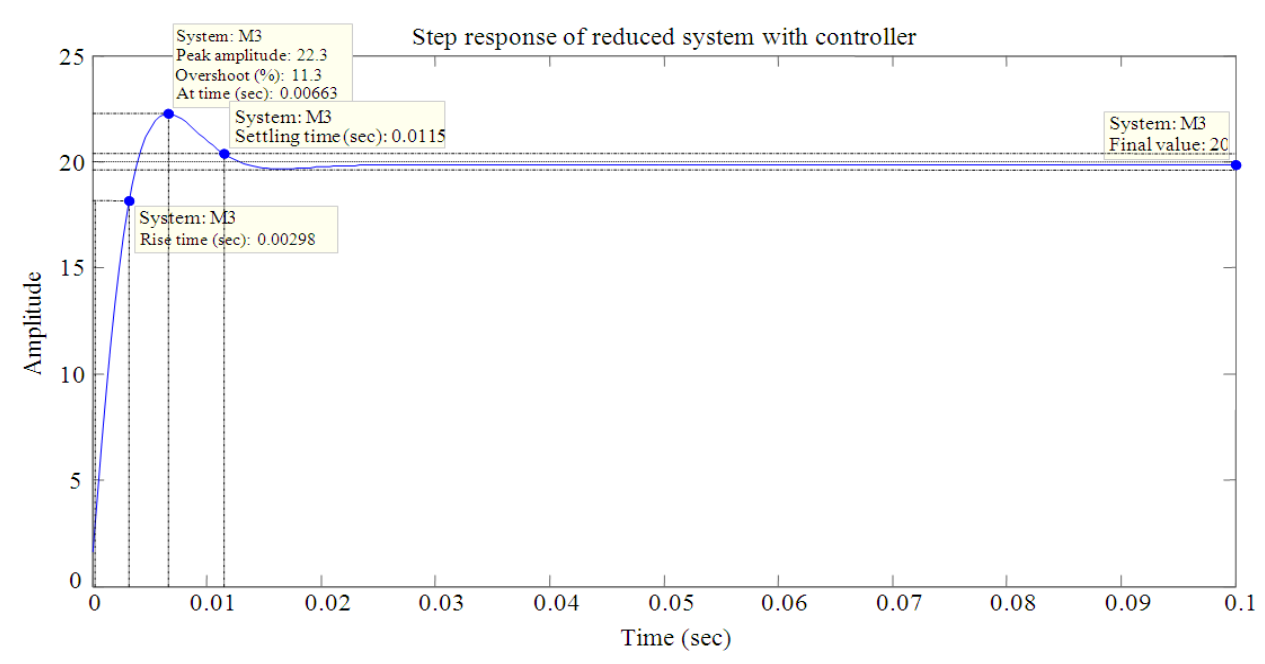

Fig. 10: Step response of reduced system with speed controller

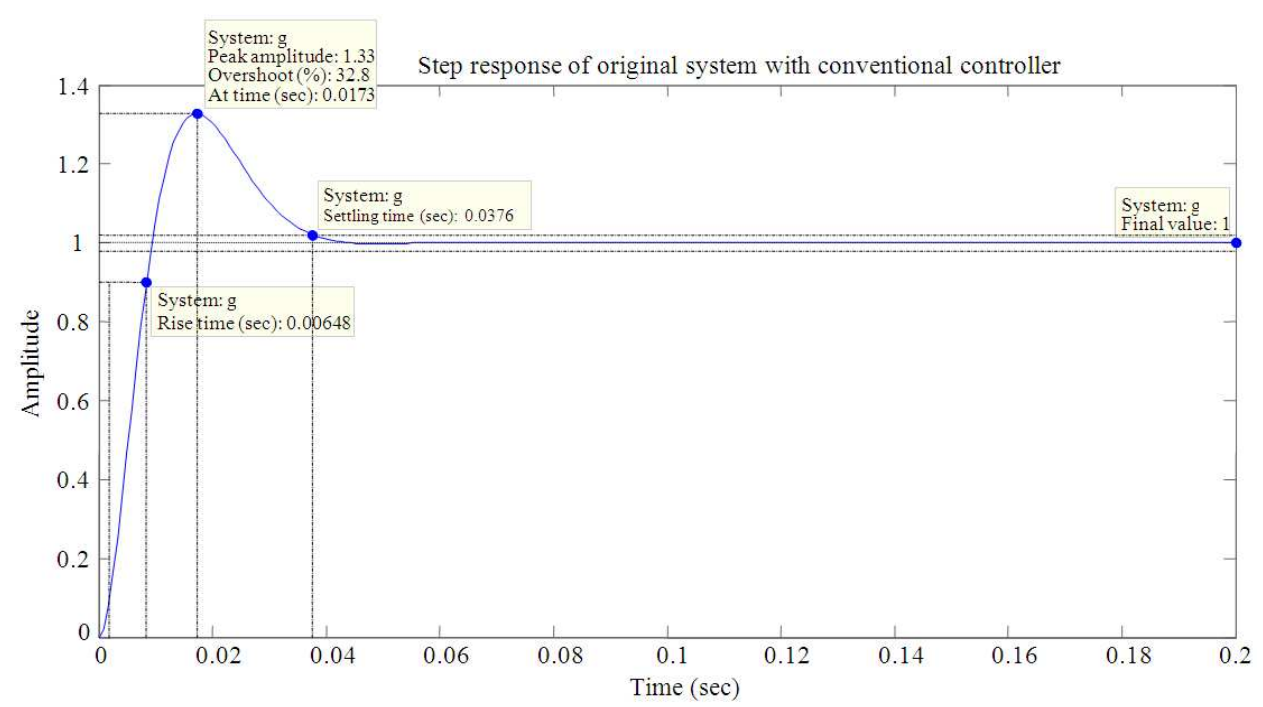

Fig. 11: Step response of original system with conventional speed controller

\section{MATERIALS AND METHODS}

For an ideal control performance by the PID controller, an appropriate PID parameter tunning is necessary (Oi et al., 2008). Mostly used PID controller tunning methods for drive controls are Zigler-Nichols method and symmetric optimum tunning method.These tunning methods are very simple, but cannot guarantee to be always effective. To surmount this inconvenience, optimization procedure may be used for the better design of controllers.

Genetic algorithm (GA) methods have been widely used in control applications.The GA method have been employed successfully to solve complex problems. The use of GA methods in the determination of the different controller parameters is effective due to their fast convergence and reasonable accuracy.This work the parameters of the PID speed controller is tuned using Genetic algorithm.

\section{RESULTS}

In this study, the performance of a PMSM drive with MOR based speed controller is evaluated on the basis of rise time, settling time and maximum overshoot. The performance of the drive system with MOR based controller has been improved as compared with the conventional PI speed controller (Singh, 2006). Table 3 gives the response of the drive system. 
Table 3: Comparision of step responses of the system with and without controller for both proposed and conventional method of speed controller

\begin{tabular}{lccc}
\hline Cases & $\begin{array}{l}\text { Rise time } \\
\left(\mathrm{t}_{\mathrm{r}}\right) \mathrm{sec}\end{array}$ & $\begin{array}{l}\text { Settling time } \\
\left(\mathrm{t}_{\mathrm{s}}\right) \mathrm{sec}\end{array}$ & $\begin{array}{l}\text { Maximum } \\
\text { overshoot }(\%)\end{array}$ \\
\hline $\begin{array}{l}\text { Original system } \\
\text { without controller }\end{array}$ & 0.4430 & 0.7920 & $2.22 \times 10-^{14}$ \\
$\begin{array}{l}\text { Reduced system } \\
\text { without controller }\end{array}$ & 0.4440 & 0.7880 & 0.00967 \\
$\begin{array}{l}\text { Original system with } \\
\text { proposed controller }\end{array}$ & 0.0027 & 0.0193 & 0.00677 \\
$\begin{array}{l}\text { Reduced system with } \\
\text { proposed controller }\end{array}$ & 0.00298 & 0.0115 & 0.00663 \\
$\begin{array}{l}\text { Original system with } \\
\text { conventional controller }\end{array}$ & 0.00648 & 0.0376 & 32.80000 \\
\hline
\end{tabular}

The simulation result (Fig. 9) shows that the response of the PMSM drive system with MOR based speed controller is better as compared to conventional method (Table 3). The speed control loop of the drive is simulated with a Conventional controller; in order to compare the performances to those obtained from the respective MOR based drive system (Rahman, 2003).

\section{DISCUSSION}

The dynamic and steady state performance of the MOR based speed controller for permanent magnet synchronous motor drive is much better than the Conventional PI speed controller. All the comparisons for the different cases are tabulated in Table 3.

\section{CONCLUSION}

The model order reduction method proposed in this study gives better approximated reduced order model for the given PMSM drive system. Because of this we get the reduced order system performance as close as possible to the higher order system response. This will result in reduction in design cost and system complexity. The method proposed in this study are applied for the Speed controller design of PMSM drive. This study focuses on the reduction of models it minimizes the complexity involved in direct design of PID Speed Controller. The approximate values for PID Controller parameters are calculated from the Genetic algorithm approach and suitably tuned to meet the required performance specifications. The tuned values of these controller parameters are attached with the original system and its closed loop response for a unit step input is found to be in good accord with the response of reduced order model.

\section{REFERENCES}

Chapman, S.J., 2002. MATLAB Programming for Engineers. 4th Edn., Cengage Learning, Stamford, ISBN-10: 9780495244493, pp: 567.
Holland, J.H., 1992. Adaptation in Natural and Artificial Systems. 1st Edn., MIT Press, Cambridge, ISBN-10: 0262581116, pp: 211.

Islam, S., F.I. Bakhsh, M. Khursheed, S. Ahmad and A. Iqbal, 2011. A novel technique for the design of controller of a vector-controlled permanent magnet synchronous motor drive. Proceedings of the Annual IEEE India Conference, Dec. 16-18, IEEE Xplore Press, Hyderabad, pp: 1-6. DOI: 10.1109/INDCON.2011.6139558

Krishnan, T. and B. Ramaswami, 1974. A fastresponse DC motor speed control system. IEEE Trans. Ind. Appli., pp: 643-651. DOI: 10.1109/TIA.1974.349214

Kuo, B.C. and F. Golnaraghi, 2003. Automatic Control Systems. 8th Edn., John Wiley and Sons, New York, ISBN: 0471134767, pp: 624.

Mahony, T., C.J. Downing and K. Fatla, 2000. Genetic Algorithm for PID Parameter Optimization: Minimizing Error Criteria. University of Stracthclyde.

Manigandan, T., N. Devarajan and S.N. Sivanandam, 2005. DESIGN of PID controller using reduced order modeL. Academic Open Int. J.

Ogata, K., 2010. Modern Control Engineering. 5th Edn., Prentice-Hall, Boston, ISBN-10: 9780136156734, pp: 894.

Oi., A., C. Nakazawa, T. Matsui, H. Fujiwara and K. Matsumoto et al., 2008. PID optimal tuning method by Particle Swarm Optimization. Proceedings of the SICE Annual Conference, Aug. 20-22, IEEE Xplore Press, Tokyo, pp: 3470-3473. DOI: 10.1109/SICE.2008.4655262

Pillay, P. and R. Krishnan, 1989. Modeling, simulation and analysis of permanent-magnet motor drives. I. The permanent-magnet synchronous motor drive. IEEE Trans. Industry Appli., 25: 265-273. DOI: $10.1109 / 28.25541$

Portone, A., 1997. Model reduction techniques in tokamak modelling. Proceedings of the 36th IEEE Conference on Decision and Control, Dec. 10-12, IEEE Xplore Press, San Diego, CA, pp: 36913696. DOI: 10.1109/CDC.1997.652430

Prasad, R., 2000. Pade type model order reduction for multivariable systems using routh approximation. Comput. Elect. Eng., 26: 445-459. DOI: 10.1016/S0045-7906(00)00002-1

Prasad, R., 2003a. Improved Pade approximants for multivariable systems using stability equation method. J. Institution Eng. 84: 161-165. DOI: 10.4103/0377-2063.48531

Prasad, R., 2003b. Linear model reduction using the advantages of Mikhailov criterion and factor division. J. Instit. Eng., 84: 9-10. 
Rahman, M.A., 2003. Real-time performance evaluation of a genetic algorithm based fuzzy logic controller for IPM motor drives. Proceedings of the 38th IAS Annual Meeting on Conference Record of the Industry Applications Conference, Oct. 1216, IEEE Xplore Press, pp: 731-737. DOI: 10.1109/IAS.2003.1257601

Ramesh, K., A. Nirmalkumar, G. Gurusamy, 2008. Order reduction by error minimization technique. International Conference on Comuting Communication and Networking, Dec. 18-20, IEEE Xplore Press, Thomas, VI, pp: 1-6. DOI: 10.1109/ICCCNET.2008.4787753

Ravichandran, C.S., 2007. Designing of PID controller for discrete time linear system using balanced approach reduced order model. Am. J. Appli. Sci., pp: 155-159. DOI: 10.3844/ajassp.2007.155.159

Shamash, Y., 1975. Linear system reduction using pade approximation to allow retention of dominant modes. Int. J. Control., 21: 257-272. DOI: 10.1080/00207177508921985

Sharma, R.K., V. Sanadhya, L. Behera and S. Bhattacharya, 2008. Vector control of a permanent magnet synchronous motor. Proceedings of the Annual IEEE India Conference, Dec. 11-13, IEEE Xplore Press, IIT Kanpur, pp: 81-86. DOI: 10.1109/INDCON.2008.4768805
Singh, B.P., 2006. Fuzzy pre-compensated PI controller for PMBLDC motor drive. Proceedings of the International Conference on Power Electronics, Drives and Energy Systems, Dec. 12-15, IEEE Xplore Press, New Delhi, pp: 1-5. DOI: 10.1109/PEDES.2006.344361

Sivanandam, S.N. and S.N. Deepa, 2009. A Comparative study using Genetic algorithm and Particle Swarm Optimization for Lower Order system modelling. Int. J. Comput. Internet Manage., 17: 1-10.

Talebi, S., B. Nikbakhtian and H.A. Toliyat, 2007. A novel algorithm for designing the PID controllers of high-speed flywheels for traction applications. IEEE Vehicle Power and Propulsion Conference, Sept. 9-12, IEEE Xplore Press, Arlington, TX, pp: 574-579. DOI: 10.1109/VPPC.2007.4544188

Thomas, N. and P. Poongodi, 2009. Position control of DC motor using Genetic algorithm based PID controller. Proceedings of the World Congress on Engineering, Jul. 1-3, IEEE Xplore Press, London.

Wallace, I.T., 1994. Verification of enhanced dynamic torque per ampere capability in saturated induction machines. IEEE Trans. Industry Appli., 30: 11931201. DOI: $10.1109 / 28.315229$ 